\title{
Copper, Boron and Vinyl Epoxides: from 1,4-Diols to Cyclopropylboronates
}

\author{
Luis Nóvoa, Laura Trulli, Alejandro Parra, and Mariola Tortosa*
}

\begin{abstract}
Herein we describe the reactivity found between vinyl epoxides and catalytically generated copperboryl complexes. By tuning the substituents of the alkene and/or the reaction conditions, 1,4-diols, allylic alcohols or cyclopropylboronates can be prepared. The stereochemical information of the vinyl epoxide is transferred to the products with high levels of stereocontrol.
\end{abstract}

Keywords: Boron · Copper catalysis · Cyclopropanes · Stereoselective synthesis · Vinyl epoxides

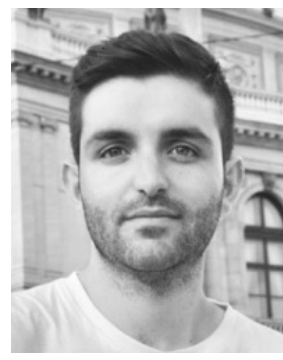

Luis Nóvoa was born in Ourense, Spain. He obtained his BS in Chemistry from the University of Vigo in 2016. As an undergraduate, he worked in total synthesis under the supervision of Prof. Ángel R. de Lera. In 2017, he obtained his master's degree at Universidad Complutense de Madrid where he worked in Medicinal Chemistry under the supervision of Dr. Carmen Gil (CIB-CSIC). Currently, he is carrying out his graduate work at Universidad Autónoma de Madrid under the supervision of Prof. Mariola Tortosa working on the development of novel borylation reactions.

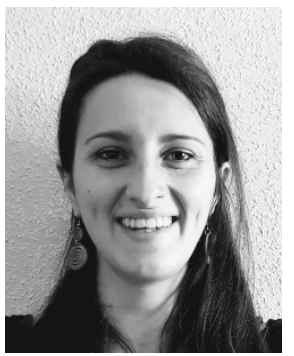

Laura Trulli studied at University of Rome "La Sapienza" obtaining her BS (2011) and $\mathrm{PhD}$ degrees in Chemistry (2016), under the supervision of Prof. Lucio Pellacani and Dr. Stefania Fioravanti. In 2017 she joined the group of Prof. Mariola Tortosa at Universidad Autónoma de Madrid as postodoctoral researcher. She is currently interested in the synthesis of novel building blocks with boron-containing stereocenters.

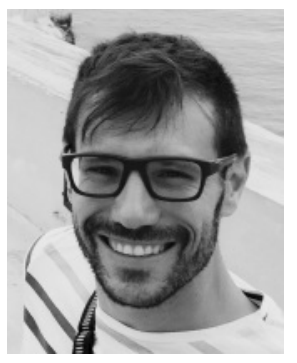

Alejandro Parra received his BS in Chemistry at the Universidad Autónoma of Madrid (Spain) in 2004. In 2006 he spent four months in the laboratory of Prof. Andrew Myers at Harvard University (USA). In 2009, he earned his PhD at the Universidad Autónoma de Madrid. After that he carried out a postdoctoral stay in Institute of Organic Chemistry, RWTHAachen (Germany), with Prof. Magnus Rueping (2009-2011). In 2015, he was promoted to Assistant Professor at Universidad Autónoma de Madrid. His research interests include boron chemistry and organocatalysis.

${ }^{\star}$ Correspondence: Prof. M. Tortosa, E-mail: mariola.tortosa@uam.es Organic Chemistry Department, Institute for Advanced Research in Chemical Sciences (IAdChem), C/ Francisco Tomás y Valiente 7, Universidad Autónoma de Madrid, 28049 Madrid, Spain

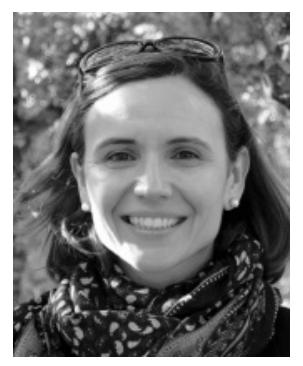

Mariola Tortosa obtained her $\mathrm{PhD}$ at the Organic Chemistry Institute (CSIC, Madrid, Spain) under the supervision of Professor Fernández de la Pradilla (2005). In 2005, she moved to The Scripps Research Institute in Florida (USA) to work as a Postdoctoral Fellow with Prof. William R. Roush. In 2008 she returned to the Organic Chemistry Institute (Madrid, Spain) as a Research Assistant. In 2011 she started her independent career at the Universidad Autónoma de Madrid (UAM) as an Assistant Professor (Ramón y Cajal Fellow). In 2017, she was promoted to Associate Professor at UAM. Biologically active compounds (natural products and drugs) are a continuous inspiration for her research which includes asymmetric catalysis, boron chemistry and the development of metal-catalyzed transformations. Since November 2019, she serves as an Associate Editor of the ACS journal Organic Letters.

Boronic esters are versatile intermediates for the preparation of a wide range of molecules through the easy functionalization of the carbon-boron bond. Traditionally, the methods to introduce boronic esters into an organic compound have been mostly based on the electrophilic nature of boron. ${ }^{[1]}$ Over the past decades, this scenario is changing, with methods that allow for the generation and use of nucleophilic boron species to form unprecedented carbon-boron bonds. ${ }^{[2]}$ In this context, the use of copper catalysis has emerged as one of the most versatile approaches to prepare boron-containing molecules. In a pioneering work, Hosomi ${ }^{[3]}$ and Miyaura ${ }^{[4]}$ disclosed that copper-boryl complexes could be formed by reaction of a copper(I) salt, preferable an alkoxide, through a $\sigma$-bond metathesis reaction (Scheme 1a). Independently, they both agreed that the in situ-generated copper-boryl complex was behaving as a formal boron nucleophile in the reaction with $\alpha, \beta$ unsaturated ketones. After them, many groups have contributed to the expansion of this field, making it possible to introduce boronic esters into organic molecules in ways that were not possible using other transition metals. [5]

Intrigued by the nucleophilic character of copper-boryl complexes, we wondered years ago how they would behave in the presence of a vinyl epoxide. Vinyl epoxides are attractive electrophiles that had been used in metal-catalyzed transformations to prepare enantiomerically enriched molecules through stereospecific transformations. ${ }^{[6]}$ In the presence of a vinyl epoxide, a nucleophile can react through a 1,2- or 1,4-addition opening up the epoxide or giving alkene addition products (Scheme 1b). What 
(a)

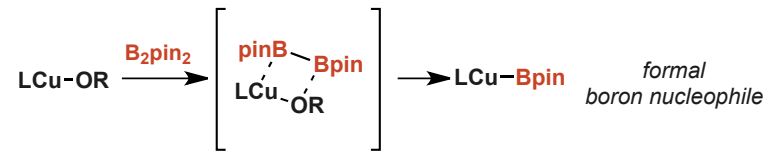

(b)<smiles>CC(C)=CC=CC(O)C[N+]#N</smiles><smiles>C=CC(CO)N=C</smiles>

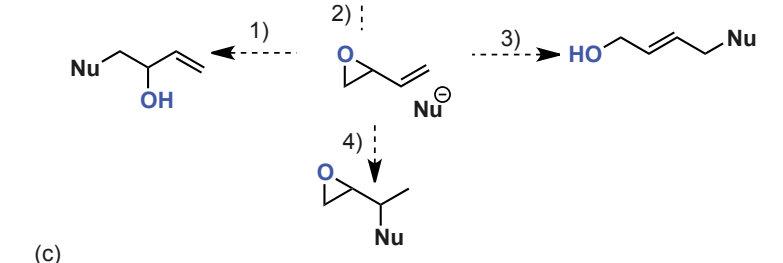

(c)

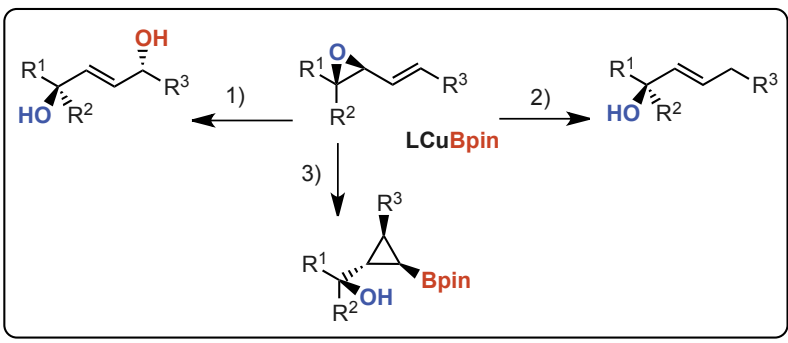

Scheme 1. (a) Generation of copper-boryl complexes. (b) Reactivity modes of vinyl epoxides with nucleophiles. (c) Copper-catalyzed borylation of vinyl epoxides.

we did not know back then is the versatility they would offer under copper-catalyzed borylation conditions (Scheme 1c). A careful study over several years has led us through a divergent pathway in which fine tuning of the substituents of the epoxide and the reaction conditions allow for the preparation of three different families of compounds: 1,4-diols, ${ }^{[7]}$ cyclopropylboronates ${ }^{[8]}$ and functionalized allylic alcohols. ${ }^{[9]}$ In this account, the details of this exciting journey will be discussed.

At the outset of our program, we envisioned that the coppercatalyzed borylation of vinyl epoxides could provide a method to prepare 1,4-diols in a stereodefined way (Scheme 2). The sequence would include a formal $\mathrm{S}_{N} 2$ ' borylation followed by oxidation of the carbon-boron bond. We reasoned that this approach would bring some advantages over the existing methods to prepare 1,4-diols. ${ }^{[10]}$ First, if the transformation were stereospecific, we would have a tool to control the syn or anti diastereoselectivity in the products, modulating the geometry of the epoxide and the alkene in the starting oxirane. Additionally, depending on the substitution pattern of the starting material, our approach could provide access to primary, secondary and tertiary diols. Finally, we envisioned that protection of the hydroxy group in $\mathbf{B}$, prior to the carbon-boron bond oxidation, would give access to orthogonally protected 1,4-diols. Overall, the method would represent a formal stereocontrolled hydrolysis of a vinyl epoxide, which is often challenging and provides mixtures of diastereomers. ${ }^{[11]}$

After initial optimization, we found that treatment of racemic epoxide $( \pm)-\mathbf{1 a}$ with $\mathrm{CuCl}(10 \mathrm{~mol} \%)$, xantphos as ligand, $\mathrm{NaO} t$-Bu (30 mol\%) and a commercially available diboron source $\left(\mathrm{B}_{2}\right.$ pin $_{2}$ ) provided hydroxy boronate $\mathbf{3}$ after three hours (Scheme

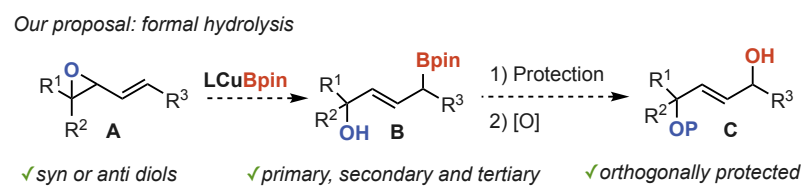

Scheme 2. Proposed synthesis of 1,4-diols.
3). Unfortunately, compound $\mathbf{3}$ proved to be unstable and all our efforts to isolate it resulted in decomposition. To bypass this difficulty we performed an in situ carbon-boron bond oxidation. After the borylation-oxidation sequence, diol ( \pm )-2a was obtained in good yield and with excellent anti/syn diastereomeric ratio. Starting from a compound with a trans geometry in the epoxide and an $E$-alkene (trans- $E$ epoxide), a 1-4-anti diol was formed. The low temperature used in the borylation was critical to control the diastereoselectivity. We then prepared a series of enantiomerically enriched vinyl epoxides (1b-1d), with different geometries in the epoxide and the alkene, to study the scope and the stereoselectivity of the transformation. We were pleased to find that tuning the geometry of the epoxide and/or the double bond, both syn or anti 1,4-diols were successfully prepared $(\mathbf{2} \mathbf{b}-\mathbf{2 d})$. Starting from trans- $Z$ vinyl epoxide $\mathbf{1 b}$ a 1,4-syn diol was obtained. Epoxides 1c and 1d show that the syn/anti diastereoselectivity could be also controlled by modifying the geometry of the epoxide. cis- $Z$ Epoxide 1c afforded the anti-diol 2c while trans- $Z$ epoxide 1d provided the anti-diastereomer $\mathbf{2 d}$. Additionally, the method allows access to not only secondary but also tertiary diols (2c and 2d).

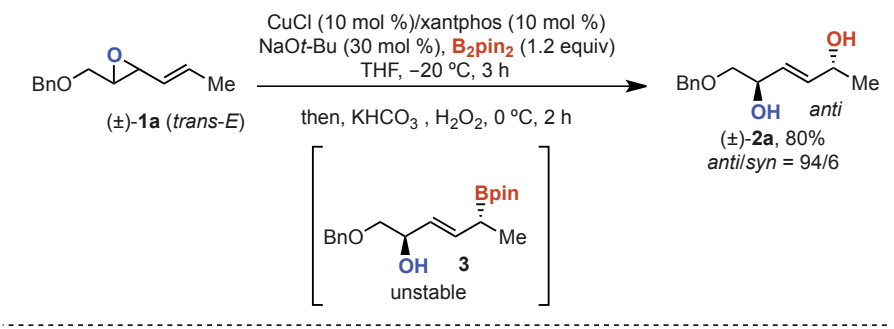

Study of the stereoselectivity:

(a)
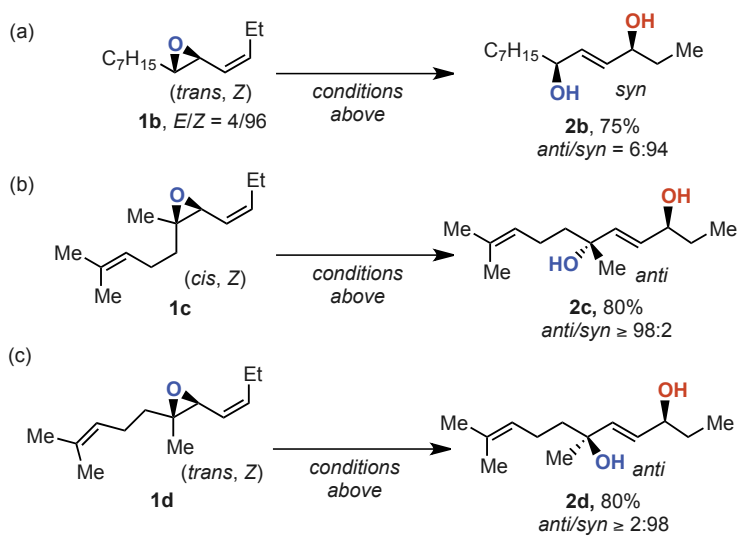

Scheme 3. Synthesis of 1,4-diols: optimized conditions and selected examples.

We then turned our attention to hydroxy boronate 3 . A possible decomposition pathway for $\mathbf{3}$ was the intermolecular interaction of the boron atom with the hydroxy group formed after the epoxide opening. We reasoned that the in situ protection of the hydroxy group would increase the stability of $\mathbf{3}$ providing a chance to isolate the boronic ester. Indeed, when we added triethyl silyl chloride after the borylation of epoxides $\mathbf{1}$, we observed the formation of protected silyloxy boronates $\mathbf{4 a}-\mathbf{4 c}$ in high yield (Scheme 4a). Importantly, compounds $\mathbf{4}$ were stable to isolation and purification. Finally, we performed the one-pot addition-protection-oxidation sequence to prepare orthogonally protected diols $\mathbf{5}$ with good overall yields (Scheme 4b).

The mechanism proposed for the copper-catalyzed borylation of vinyl epoxides is shown in Scheme 5. First, a phosphine-copper-boryl complex is formed by reaction of a copper(I) alkoxide and a diboron compound through a $\sigma$-bond metathesis reaction. Then, insertion of the alkene into the $\mathrm{Cu}-\mathrm{B}$ bond takes place fol- 
a) One-pot borylation-protection:
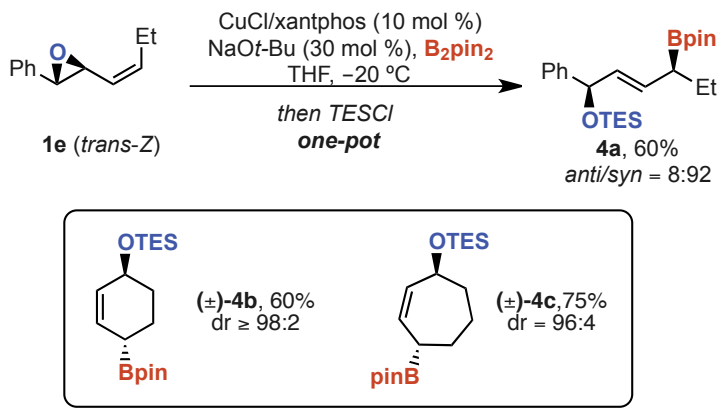

b) One-pot borylation-protection-oxidation:
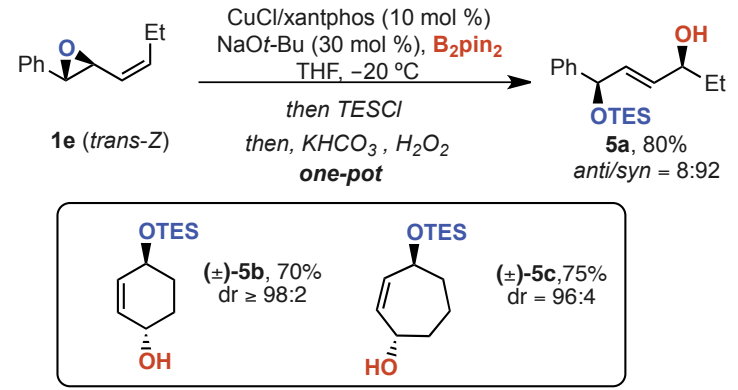

Scheme 4. Synthesis of orthogonally protected 1,4-diols.

lowed by $\beta$-oxygen elimination and ring opening to form copper alkoxide E. The observed stereochemical outcome could be explained by an anti-attack of the boryl-copper intermediate to an allylic epoxide in an $s$-trans conformation. ${ }^{[12]}$ Finally, reaction of $\mathbf{E}$ with $\mathrm{B}_{2} \operatorname{pin}_{2}$ allows regeneration of the catalytic cycle.

One of the limitations found in the method is that vinyl epoxides with aromatic substituents in the double bond $\left(\mathrm{R}^{3}=\right.$ aryl $)$ did not provide the expected 1,4-diol (Scheme 6). When we exposed epoxide 1f to the optimized conditions (left arrow, Scheme 6) a complex mixture of products was obtained. However a more careful examination of the crude product allowed us to identify cyclopropylboronate $\mathbf{6 a}$, in moderate yield, as a single diastereomer. ${ }^{[13]}$ Interestingly, in the presence of methanol, under otherwise iden-

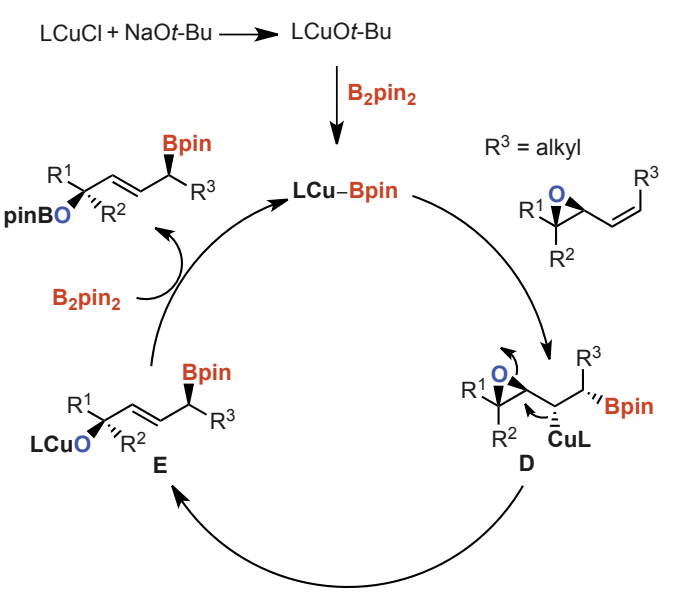

Scheme 5. Proposed mechanism for the copper-catalyzed borylation of vinyl epoxides.

tical conditions, allylic alcohol 7a was formed. Although these were not the desired pathways, they were both appealing transformations. Compound $\mathbf{6 a}$ is a unique cyclopropane with four contiguous stereocenters and a boryl moiety, which could be further modified through $\mathrm{C}-\mathrm{B}$ bond functionalization. On the other hand, allylic alcohol 7a is the product of a formal 1,4-reduction of epoxide 1f, cleanly formed without the use of strong reductants (right arrow, Scheme 6). Similar transformations required the use of super stochiometric amounts of freshly prepared $\mathrm{SmI}_{2}$ or $\mathrm{Mg}$ in methanol.[14]

Thinking about possible mechanistic pathways, we reasoned that the aromatic group in the alkene was changing the regiochemistry in the insertion step, placing the boryl moiety next to the epoxide. Additionally, the stereochemical outcome for the formation of $6 \mathbf{a}$ seemed to indicate a syn insertion relative to the epoxide in an s-trans conformation to provide $\mathbf{F}$. This outcome could be favored by coordination of the oxygen of the epoxide to the boron atom. From $\mathbf{F}$, in the absence of a proton source, cyclopropylboronate $\mathbf{G}$ would be formed through an intramolecular $\mathrm{S}_{\mathrm{v}} 2$ reaction. The cis relationship between the aryl group and the boron atom may result from a W-shaped transition state. ${ }^{[15]}$ Reaction of $\mathbf{G}$ with the diboron compound generates again a catalytically active

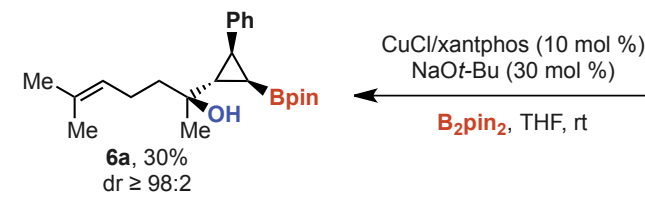

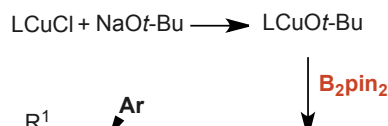
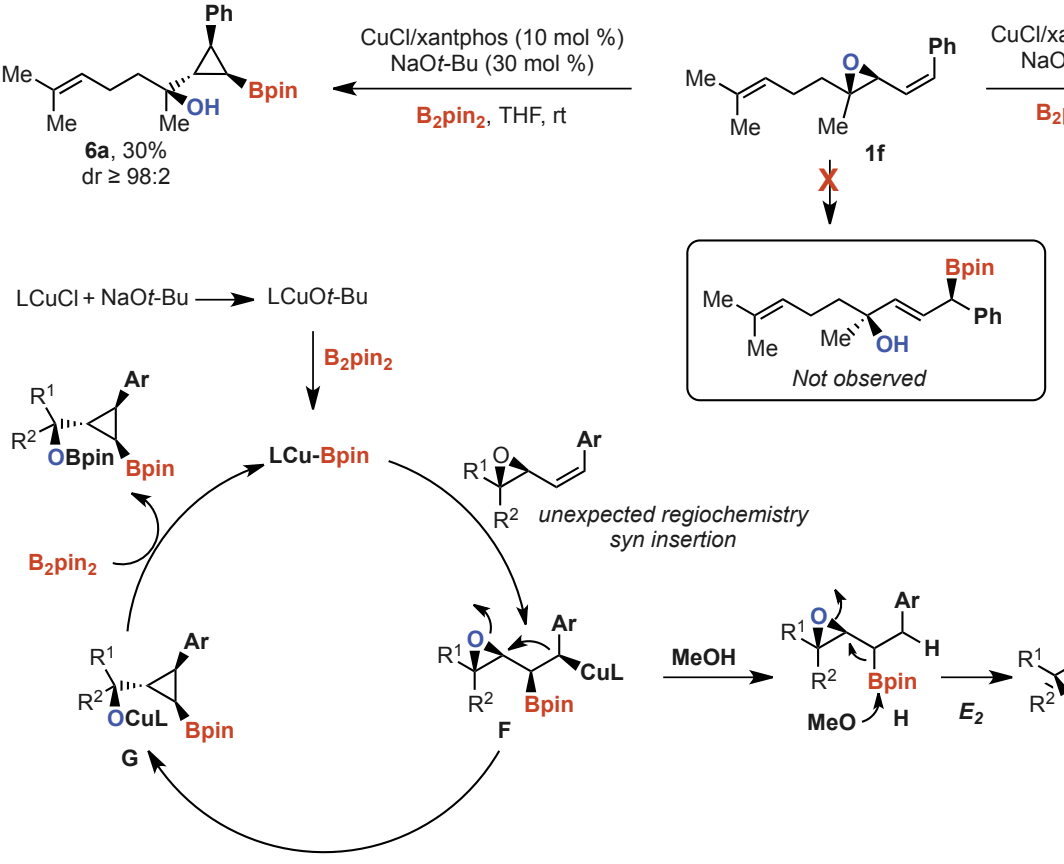

$\mathrm{B}_{2} \mathrm{pin}_{2}, \mathrm{MeOH}, \mathrm{rt}$

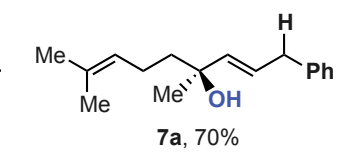

with MeOD

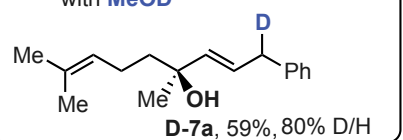

Scheme 6. Unexpected formation of cyclopropylboronates and allylic alcohols. 
copper-boryl complex. In the presence of methanol, intermediate $\mathbf{F}$ is protonated to provide epoxide $\mathbf{H}$. This intermediate undergoes a spontaneous base-promoted $\beta$-oxygen elimination to afford an allylic alcohol. Using deuterated methanol, allylic alcohol D-7a was obtained, with deuterium incorporation at the benzylic carbon. This result supports the proposed mechanism.

Driven by our interest in the synthesis of functionalized small rings, ${ }^{[16]}$ we started to optimize the formation of cyclopropylboronate 6a (Scheme 7). We were pleased to find that using one equivalent of $\mathrm{KO} t$ - $\mathrm{Bu}$ as base increased the yield to $81 \%$ without compromising the diastereoselectivity. The transformation was shown to be highly dependent on the ligand, and only xantphos provided the cyclopropane derivative. With other monodentate and bidentate ligands such as $\mathrm{Cy}_{3} \mathrm{P}, \mathrm{Ph}_{3} \mathrm{P}$ or dppBz we only observed formation of diene $\mathbf{8}$. This undesired product could be formed via base-promoted elimination of the boryl moiety with subsequent ring opening, followed by isomerization of the resulting allyl copper intermediate and $\beta$-oxygen elimination (Scheme 7).
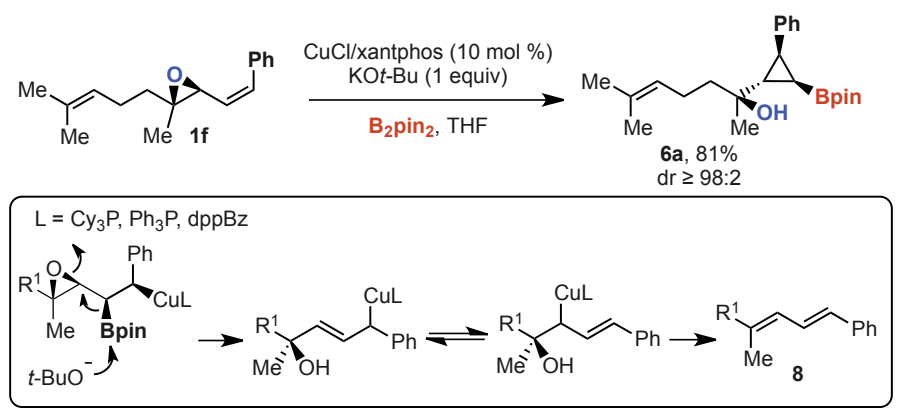

Scheme 7. Stereoselective synthesis of cyclopropylboronates from vinyl epoxides.

The method showed good tolerance to different substituents on the aromatic ring and some representative examples are shown in Scheme 8. Importantly, vinyl epoxides with an $E$ alkene $(\mathbf{1 g}$, 1h) gave access to cyclopropyl boronates with a trans relationship between the aryl group and the boron atom $(\mathbf{6 e}, \mathbf{6 f})$. These results revealed that the reaction is stereospecific. As expected, when the epoxide is enantiomerically enriched, the enantiomeric ratio is transferred from the starting material to the products.

One of the attractive features of the products is the possibility to further functionalize the boronic ester (Scheme 9). The Matteson homologation of boronate $\mathbf{9}$, followed by oxidation of the $\mathrm{C}-\mathrm{B}$ bond afforded compound $\mathbf{1 0}$, in which the boronic es-
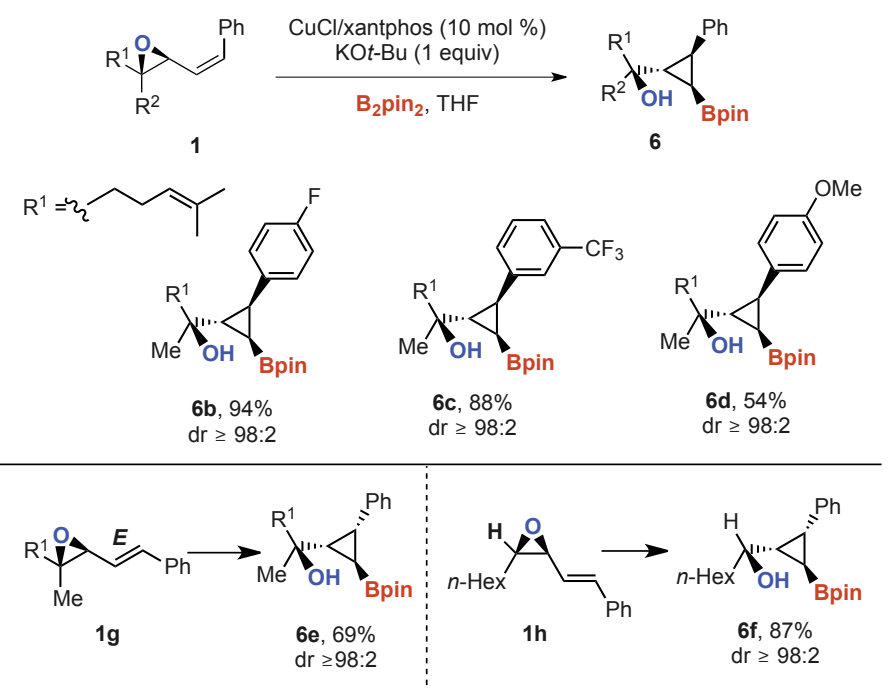

Scheme 8. Synthesis of cyclopropylboronates: selected examples. ter has been effectively replaced by a hydroxy methylene group $\left(\mathrm{CH}_{2} \mathrm{OH}\right)$. Additionally, starting from cyclopropylboronate 9, a Suzuki-Miyaura cross coupling reaction afforded cyclopropane 11 with retention of the configuration in the newly formed stereocenter.

a) Homologation-oxidation sequence

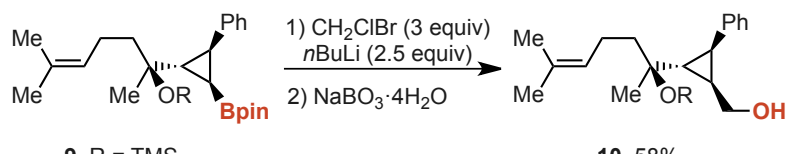

9, $R=T M S$

$10,58 \%$ (two steps)

b) Suzuki-Miyaura cross-coupling reaction

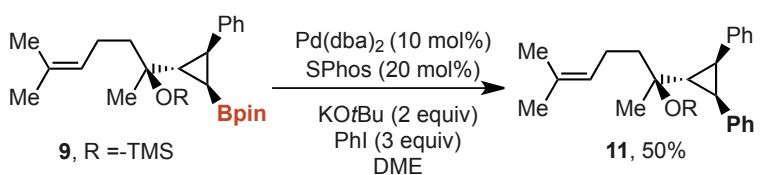

Scheme 9. Functionalization of the carbon-boron bond.

As mentioned above, when the borylation of $\mathbf{1 f}$ was carried out in the presence of a proton source, allylic alcohol 7a was obtained instead of cyclopropane 6a (Scheme 6). After some experimentation we observed that the best yield for compound 7a was observed using $\mathrm{CuCl}(10 \mathrm{~mol} \%)$, xantphos as ligand, 0.5 equiv of $\mathrm{NaO} t-\mathrm{Bu}$ and methanol (4 equiv.) as a proton source (Scheme 10). The formal reduction worked well not only with different aromatic groups in the alkene but also with electron-withdrawing groups such as esters (7e) and nitriles (7d). Additionally, we set up several competition experiments to compare our method with the use of $\mathrm{SmI}_{2}$ or $\mathrm{Mg} / \mathrm{MeOH}$. When we carried out the formal reduction of $\mathbf{1 f}$ in the presence of an aryl iodide, an aryl bromide or acetophenone, we only detected formation of 7a, without observing significant borylation of the competitive substrate.

Epoxyenynes are a particular subclass of starting epoxides because they present two functional groups susceptible to react in the presence of a copper-boryl complex: an alkene and an alkyne. When we used 1.1 equivalents of the diboron compound, the alkene moiety reacted selectively to provide the 1,4-reduction products $\mathbf{7 h}$ and $\mathbf{7 i}$ (Scheme 11). Moreover, with an excess of $\mathrm{B}_{2}$ pin $_{2}$ a regioselective borylation of the alkyne takes place after the formal 1,4-reduction. Skipped dienes $\mathbf{1 2}$ are attractive intermediates that would be difficult to prepare using other methods. These compounds have in their structure a stereodefined alkene with a boryl and a silyl substituent that could be functionalized orthogonally through selective cross-coupling. ${ }^{[17]}$

In summary, we present here the stereoselective synthesis of 1,4-diols, cyclopropylboronates and allylic alcohols starting from vinyl epoxides, under copper-catalyzed borylation conditions. Vinyl epoxides with an alkyl group in the alkene are cleanly transformed into 1,4-diols through a borylation-oxidation sequence. The syn or anti diastereoselectivity of the process can be tuned by proper selection of the geometry of the epoxide and the double bond in the starting material. Surprisingly, vinyl epoxides with an aryl instead of an alkyl group afforded cyclopropylboronates with four contiguous stereocenters with complete control of the diastereoselectivity. Finally, products resulting from the formal 1,4-reduction of the vinyl epoxide were formed in the presence of a proton source, under otherwise similar copper-catalyzed borylation conditions.

\section{Acknowledgements}

We thank the European Research Council (ERC-337776) and MINECO (CTQ2016-78779-R) for financial support. 


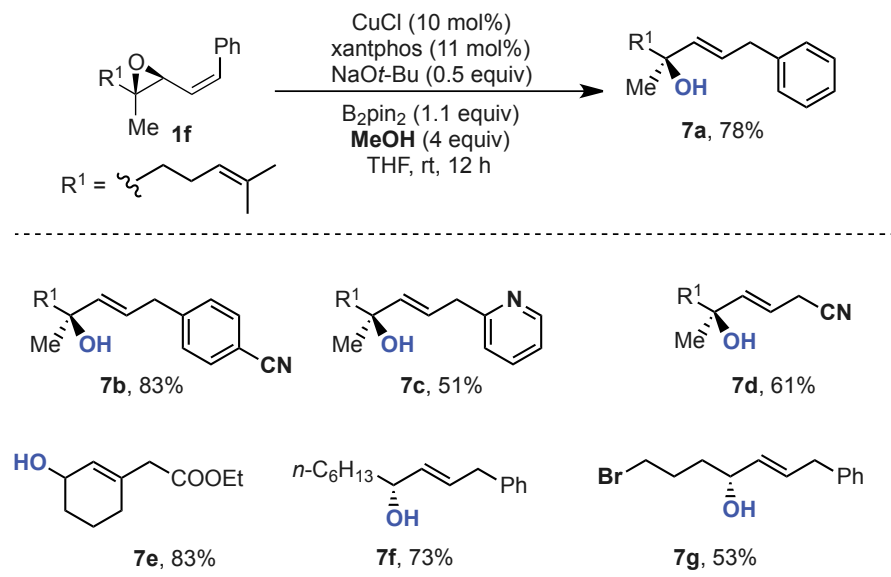

Scheme 10. Copper-catalyzed formal 1,4-reduction of vinyl epoxides.
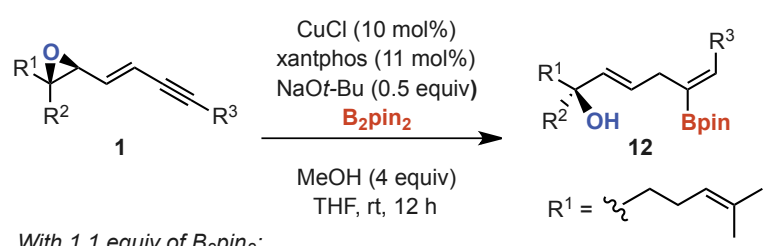

With 1.1 equiv of $B_{2}$ pin $_{2}$ :<smiles>[R1][C@](C)(O)/C=C/CC#C[SiH2]C</smiles>

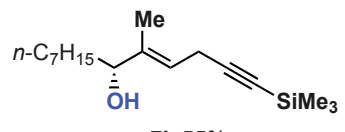

With 3 equiv of $B_{2}$ pin $_{2}$ :

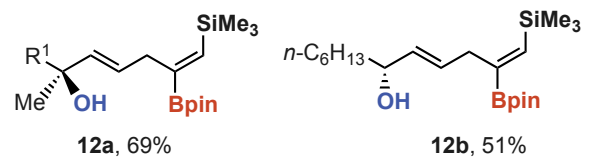

Scheme 11. Synthesis of skipped enynes and dienes.

Received: July 30, 2020

[1] D. G. Hall, 'Boronic Acids-Preparation and Applications in Organic Synthesis Medicine and Material', Ed. D. G. Hall, Wiley-VCH, Weinheim, 2011.

[2] J. Cid, H. Gulyas, J. J. Carbó, E. Fernández, Chem. Soc. Rev. 2012, 41, 3558.

[3] H. Ito, H. Yamanaka, J. Tateiwa, A. Hosomi, Tetrahedron Lett. 2000, 41, 6821.

[4] a) K. Takahashi, T. Ishiyama, N. Miyaura, Chem. Lett. 2000, 29, 982. b) K. Takahashi, T. Ishiyama, N. Miyaura, J. Organomet. Chem. 2001, 47, 625.

[5] a) For recent reviews, see: a) E. C. Neeve, S. J. Geier, I. A. I. Mkhalid, S. A. Westcott, T. B. Marder, Chem. Rev. 2016, 116, 9091. b) D. Hemming, R. Fritzemeier, S. A. Westcott, W. L. Santos, P. G. Steel, Chem. Soc. Rev. 2018, 47, 7477 .

[6] For a review, see: a) M. Pineschi, F. Bertolini, V. Di Bussolo, P. Crotti, Curr. Org. Synth. 2009, 6, 290. b) J. He, J. Ling, P. Chiu, Chem. Rev. 2014, 114, 8037.

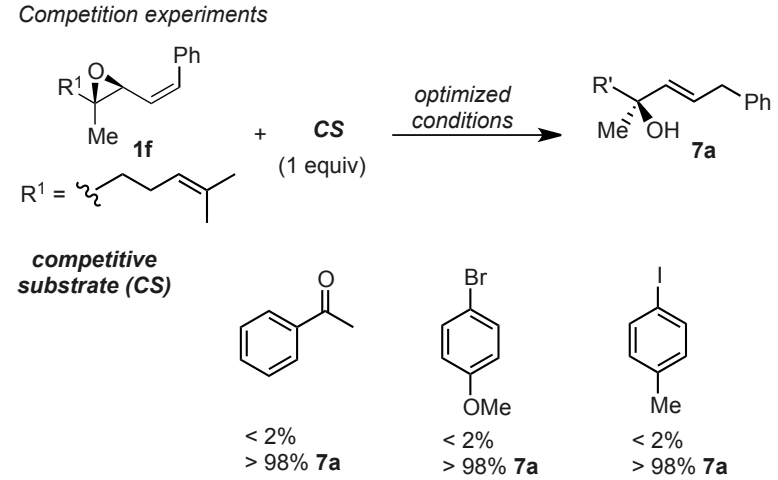

[7] M. Tortosa, Angew. Chem. Int. Ed. 2011, 50, 3950.

[8] L. Amenós, L. Trulli, L. Nóvoa, A. Parra, M. Tortosa, Angew. Chem. Int. Ed. 2019, $58,3188$.

[9] L. Amenós, L. Nóvoa, L. Trulli, A. Parra, M. Tortosa, ACS Catal. 2019, 9, 6583.

[10] For selected examples, see: a) H. Fujioka, H. Kitagawa, Y. Nagatomi, Y. Kita, J. Org. Chem. 1996, 61, 7309. b) M. Amador, X. Ariza, J. Garcia, J. Ortiz, Tetrahedron Lett. 2002, 43, 2691. c) K. M. Knapp, B. Goldfuss, P. Knochel, Chem. Eur. J. 2003, 9, 5259. d) Y. Kobayashi, M. Asano, S. Yoshida, A. Takeuchi, Org. Lett. 2005, 7, 1533. e) M. K. Gurjar, C. Pramanik, D. Bhattasali, C. V. Ramana, D. K. Mohapatra, J. Org. Chem. 2007, 72, 6591. f) H. E. Burks, L. T. Kliman, J. P. Morken, J. Am. Chem. Soc. 2009, 131, 9134. g) M. B. Binanzer, G. Y. Fang, V. K. Aggarwal, Angew. Chem. Int. Ed. 2010, 49, 4264 .

[11] R. E. Conrow, Org. Lett. 2006, 8, 2441.

[12] J. A. Marshall, Chem. Rev. 1989, 89, 1503.

[13] For copper-catalyzed borylative exo-cyclizations of alkenes, see: a) H. Ito, T. Toyoda, M. Sawamura, J. Am. Chem. Soc. 2010, 132, 5990. b) K. Kubota, E. Yamamoto, H. Ito, J. Am. Chem. Soc. 2013, 135, 2635. c) J. Royes, S. Ni, A. Farré, E. La Cascia, J. J. Carbó, A. B. Cuenca, F. Maseras, E. Fernández, ACS Catal. 2018, 8, 2833.

[14] a) G. A. Molander, B. E. La Belle, G. Hahn, J. Org. Chem. 1986, 51, 5259. b) K. Otsubo, J. Inanaga, M. Yamaguchi, Tetrahedron Lett. 1987, 28, 4437. c) C. S. Pak, E. Lee, G. H. Lee, J. Org. Chem. 1993, 58, 1523. d) J. S. Yadav, T. Shekharam, D. Srinivas, Tetrahedron Lett. 1992, 33, 7973.

[15] S. Norsikian, I. Marek, J.-F. Poisson, J. F. Normant, J. Org. Chem. 1997, 62, 4898.

[16] A. Parra, L. Amenós, M. Guisán-Ceinos, A. López, J. L. García Ruano, M. Tortosa, J. Am. Chem. Soc. 2014, 136, 15833. b) M. Guisán-Ceinos, A. Parra, V. Martín-Heras, M. Tortosa, Angew. Chem. Int. Ed. 2016, 55, 6969.

[17] Y. M. Chae, J. S. Bae, J. H. Moon, J. Y. Lee, J. Yun, Adv. Synth. Catal. 2014, $356,843$.

\section{License and Terms}

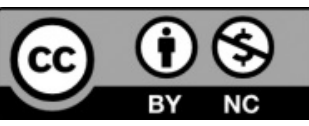

This is an Open Access article under the terms of the Creative Commons Attribution License CC BY_NC 4.0. The material may not be used for commercial purposes.

The license is subject to the CHIMIA terms and conditions: (http:// chimia.ch/component/sppagebuilder/?view=page \&id=12).

The definitive version of this article is the electronic one that can be found at https://doi.org/10.2533/chimia.2020.852 